\title{
Políticas empresarialistas en los procesos de gentrificación en la Ciudad de México ${ }^{1}$
}

\author{
Patricia Olivera ${ }^{2}$ y Víctor Delgadillo ${ }^{3}$
}

\begin{abstract}
RESUMEN
La reestructuración urbana en la Ciudad de México desde fines de la década de 1980 ha dado lugar a diversos procesos asociados con la gentrificación, apoyada en la gestión urbana empresarialista, la cual ha facilitado la realización de megaproyectos inmobiliarios, la revitalización de barrios urbanos, la fragmentación del tejido social y el desplazamiento de población residente, trabajadora y de algunas actividades tradicionales en aquellos espacios urbanos que han sido revalorizados. La complejidad de estos procesos urbanos lleva, en primer lugar a una necesaria reflexión y debate teórico para entender estas profundas transformaciones urbanas. Para lo cual se examinan las políticas urbanas neoliberales recientes y su vinculación con los diversos procesos de gentrificación, sus formas, intensidades y temporalidades diferenciadas y se profundiza en el análisis del Centro Histórico y otros barrios paradigmáticos de la ciudad interior.
\end{abstract}

Palabras clave: Gentrificación en la Ciudad de México, megaproyectos urbanos, políticas empresarialistas.

\begin{abstract}
The urban restructuring in Mexico City since the late 1980s has led to various processes associated with gentrification. Urban entrepreneurial management has facilitated the production of real estate megaprojects, the revitalization of urban neighborhoods, the fragmentation of the social fabric and the displacement of resident population, workers, and some traditional activities of those urban spaces that have been revalued. The complexity of these urban processes leads to a theoretical reflection and debate necessary to understand these profound urban transformations. Therefore, the recent neoliberal urban policies and their relationship to the presence of various processes of gentrification, its forms, intensities and different temporalities are examined herein. The article deals with the analysis of the Historic downtown and other paradigmatic neighborhoods of the inner city.
\end{abstract}

Key words: Gentrification in Mexico City, urban megaprojects, entrepreneurial policies.

\footnotetext{
1 Artículo recibido el 30 de septiembre de 2013 aceptado el 24 de marzo de 2014 y corregido el 2 de julio de 2014.
}

2 Departamento de Geografía, Universidad Nacional Autónoma de México (México). E-mail: oliverap@unam.mx.

3 Colegio de Humanidades y Ciencias Sociales, Universidad Autónoma de la Ciudad de México (México). E-mail: Victor_Delgadill@hotmail.com. 
Los procesos de reestructuración y neoliberalización en la Ciudad de México desde fines de la década de 1980 se caracterizan por una gestión urbana pro empresarialista. Estos procesos han conducido a la gentrificación siguiendo diversas formas de ocupación, promociones inmobiliarias y con distintas temporalidades e intensidades. Este texto propone nuevos debates sobre la gentrificación en Europa y América Latina desde la red de investigación "Contested Cities", en términos de contribuir con indagaciones y nuevas interpretaciones acerca de procesos asociados a la gentrificación, considerando en particular la Ciudad de México.

En el contexto neoliberal, la gentrificación forma parte de los procesos de reestructuración urbana cíclica a partir del interés de inversionistas inmobiliarios y financieros en invertir en antiguos barrios urbanos apoyados a través de la gestión público- privada para obtener los beneficios que reproducen el capital. Esto ha permitido a los grandes inversionistas privados la captura de las rentas urbanas potenciales y ha implicado la sustitución directa e indirecta de población residente con nuevos segmentos de clase social, así como nuevas formas de consumo y apropiación de la ciudad. Estos procesos se insertan en el urbanismo empresarialista cuya gestión urbana pública y público-privada favorece los intereses del mercado, como ocurre en otras ciudades.

El primer apartado se suma al debate teórico sobre la gentrificación en América Latina y España y se presenta una propuesta relativa a la discusión de las políticas públicas y su asociación con intereses privados para favorecer los procesos de gentrificación. Posteriormente se expone el contexto general de la reestructuración urbana que ha sufrido la capital mexicana, a partir de los megaproyectos inmobiliarios de alto impacto en el marco de la neoliberalización que ocurre desde la década de 1980. Esto plantea la articulación de las políticas públicas con los megaproyectos a través de las distintas formas de gestión que claramente expresan el urbanismo neoliberal pro empresarialista. El tercer apartado se centra en las diferencias particulares de la gestión en algunos barrios paradigmáticos de la ciudad interior que muestran distintos procesos de gentrificación en la Ciudad de México: la zona rehabilitada del Centro Histórico, las zonas y corredores urbanos de las colonias Roma y Condesa en la Delegación Cuauhtémoc, la "Ciudad progresiva" en el pueblo de Xoco en Benito Juárez y la zona denominada "Nuevo Polanco" en Miguel Hidalgo.

La pregunta central que guía esta investigación, cuyos resultados preliminares presentamos en este artículo, se refiere a ¿Qué acciones empresariales han sido favorecidas por el Estado y están propiciando la gentrificación de la Ciudad de México a partir de la década de 1990? Se desprenden de esta, las preguntas particulares ¿Cuál es la oferta inmobiliaria privada y su relación con los cambios morfológicos urbanos? ¿Cuáles son las formas de gestión de los programas públicoprivados de "remodelación, rehabilitación, recuperación, rescate" y nueva edificación? ¿Qué formas de resistencia social se presentan en estas zonas altamente valoradas por sus significados económicos y culturales?

\section{La gentrificación y el empresarialismo urbano}

En este trabajo se consideran dos procesos centrales de la gentrificación para su estudio en la ciudad de México, la gestión urbana y la presencia de desplazamientos sociales directos e indirectos. Por una parte, se analiza la gestión pública y las formas de asociación con los intereses privados para el desarrollo de proyectos inmobiliarios que son privados; y por otra, las problemáticas sociales que están generando, en particular el desplazamiento derivado de las afectaciones en los barrios por la presencia de actividades y usos de alto impacto, lo cual se oculta por parte de las autoridades del Distrito Federal y, en algunos casos, se emplea la fuerza pública para acallar las protestas de los vecinos y organizaciones en contra de tales emprendimientos inmobiliarios.

En la red "Contested Cities" hemos iniciado discusiones acerca de la gentrificación, sus manifestaciones y muestras de sus diversidades en las ciudades de América Latina y España. En ese marco Janoschka et al. (2013) reúnen varias formas encontradas en la literatura respectiva: 
- La "gentrificación simbólica", vinculada con la inversión privada para la conservación de los centros y barrios históricos promovidos para el entretenimiento y consumo cultural; la reubicación del comercio informal que ocupa las calles y plazas públicas, las políticas contra la violencia y la inseguridad, y el fomento del turismo.

- La "gentrificacion dirigida por el Estado e inducida por el turismo".

- El papel de las "políticas neoliberales de gentrificación" a través de la inversión estatal, que abiertamente favorecen las ganancias privadas, atraen a nuevos usuarios, residentes o turistas, y desplazan a la población con menores ingresos.

- La "gentrificación en zonas de uso productivo y su reconversión" conducida por el mercado inmobiliario en las áreas urbanas centrales o periféricas.

- En particular, para las ciudades españolas se encuentra la "gentrificación e inmigración trasnacional".

- Las "nuevas geografías de la gentrificación" en espacios rurales y provinciales.

Se destacan para su reflexión y debate, los significados y dimensiones de la gentrificación en América Latina en donde se expresan caracterizaciones que subrayan los dos procesos enfocados en este trabajo, acerca de la gestión urbana y el desplazamiento social, entre otros, expresados por investigadores latinoamericanos:

- Las transformaciones urbanas aceleradas durante la gestión neoliberal en torno a la creación de nuevas centralidades para la valorización de espacios urbanos donde es posible la apropiación de las rentas potenciales (Hidalgo, 2010), asimismo para garantizar encadenamientos productivos y con ello la fijación capitales corporativos en la ciudad de México, como espacio de poder y consumo (Olivera, 2008).

- La verticalización de las edificaciones en áreas centrales y adyacentes de Santiago, que aprovechan las pautas diferenciadas demográficas, migratorias, diferenciales de renta y de reestructuración productiva aceleradas (López Morales et al., 2012).

- La multiplicación de los servicios productivos para las empresas en São Paulo, donde florecen otros servicios alrededor, como una expresión de la sobrevaloración en unos sitios y la desvalorización en otros en las ciudades latinoamericanas (Lencioni, 2008).

- Los impactos urbanos de las universidades, asociadas con la renovación urbana residencial, constituyen en Bogotá los detonantes del crecimiento y consolidación de barrios bohemizados, donde se amplían actividades comerciales y de consumo, como el caso de la Candelaria, un barrio colonial, donde se ha realizado un intenso proceso de revitalización urbana (Jaramillo, 2006).

Considerando que la gestión urbana en México involucra en primer lugar la atracción de movimientos de capital y, por tanto, se traslapan intereses locales y externos, se retoma el planteamiento de Milton Santos (2002) acerca de la dinámica del capital en la economía urbana latinoamericana en los dos circuitos del capital, superior e inferior. Los desarrollos inmobiliarios estudiados en la ciudad de México, se ubican en el circuito superior del capital, porque responden a los intereses de capitales trasnacionalizados los cuales buscan los más altos rendimientos en los lugares propicios para extraer valor, incluyendo aquellos de las periferias del sistema. Esto genera el incremento de las rentas del suelo capitalizadas y los grupos locales pueden verse beneficiados, pero estos son generalmente los de más alta renta per cápita. La elevación de las rentas diferenciales con las nuevas inversiones propician la reproducción de profundos contrastes y polarización social con formas de fragmentación del tejido social en las ciudades de América Latina (Olivera, 2013a), donde se trastroca la segregación residencial, de clase y étnica y donde se gestan movimientos sociales urbanos. Por ejemplo, en los centros históricos de Santiago de Chile y de Buenos Aires, por un lado se "revitalizan" y por otro, se aloja una creciente inmigración peruana, paraguaya y boliviana, respectivamente (Hidalgo, 2010; LópezMorales et al., 2012). En el centro de Bogotá, la población flotante representa alrededor del $82 \%$ de los tres niveles de ingresos más bajos y el 1,3\% del estrato más alto (Jaramillo, 2006). En São Paulo, migrantes y en general población empobrecida sin techo se encuentra enclavada en el centro, al lado de lujosas edificaciones verticales (Carlos, 2001); en 
la Ciudad de México, en la nueva centralidad de enclave Santa Fe se encuentran dos desarrollos populares que han resistido las cuantiosas inversiones inmobiliarias desde la década de 1990 (Olivera, 2013b).

Se destacan aquí dos procesos centrales de la gestión urbana gentrificadora en la Ciudad de México, por una parte las formas de desalojo cuyos antecedentes encontramos en el Centro Histórico, dividido entre la ciudad de los palacios, con abundantes y suntuosas edificaciones alrededor de la plaza central y calles comerciales hacia el poniente, y bordeándola por el oriente de norte a sur, la ciudad de los tugurios, con los barrios populares de La Merced, Guerrero, Morelos, Tepito, Peralvillo y Tlatelolco, todos ellos en la delegación central Cuauhtémoc. En estos barrios surgieron en las décadas de 1970 y 1980 movimientos urbanos populares que compartieron experiencias de lucha contra los planes de regeneración urbana con una "capacidad avanzada para formular propuestas propias para la defensa social de sus barrios", ya que hubo procesos de desalojo y también diversos intentos en varios momentos (ver Ramírez Saiz, 1986). Por otra parte, la asociación público privada y su articulación con políticas neoliberales en las tradicionales y nuevas centralidades urbanas en la ciudad de México, valorizadas por los grandes proyectos inmobiliarios, los que conjugan activos económicos existentes y creados, como las diversas arquitecturas patrimonializadas y su mercantilización; a esto se añade la sustitución de usos y de funciones en declive por otros más rentables. Con lo cual se producen nuevos barrios con procesos gentrificadores en donde concurren capitales que crean nuevos megaproyectos de servicios, comerciales y residenciales. El común denominador de estos proyectos es la intencionalidad que los sustenta: la obtención de rentas potenciales, las ganancias por la localización, aprovechando los mercados y la promoción de políticas neoliberales que otorgan facilidades a la inversión privada: exenciones de impuestos, programas concesionados a privados, normatividad urbana que permite la intensificación de usos, entre otras, en el marco de la gestión empresarialista que busca atraer capitales y fijarlos en la ciudad (Olivera, 2011). En este contexto, la teoría de la gentrificación desde la perspectiva crítica aborda procesos de ex- clusión de clase (Smith, 1996), de reproducción de capital, por lo que resulta importante caracterizarlos en cuanto a las condiciones objetivas y subjetivas respecto a las afectaciones a las clases trabajadoras en general, y en particular desempleados y trabajadores informales, frente los intereses de la obtención de beneficios por parte de los desarrolladores, quienes se apropian no solo de las rentas del suelo, sino de los beneficios que se derivan de las actividades favorecidas en esos lugares, los capitales inmobiliarios dan pie a la entrada a la circulación del capital en sus diversos circuitos; cuantiosas inversiones públicoprivadas y estrategias de mercadotecnia, lo cual a su vez, se asocia con la ideología y los imaginarios urbanos para atraer a los nuevos residentes, sean comerciantes, profesionistas, servidores públicos (Olivera, 2013).

Debido a estos procesos y a la ausencia de una política de vivienda social vinculada con la demanda real en la Ciudad de Méxi$\mathrm{CO}^{4}$ han surgido diversos tipos de movilizaciones sociales, en parte directamente por las afectaciones derivadas de las obras de infraestructura vial y los desalojos aislados, y por otra, los desplazamientos indirectos a raíz de la elevación de las rentas, los alquileres y nuevas construcciones debido a la inyección de capital por los programas de remodelación y megaproyectos inmobiliarios. Esto se abordará en detalle en otros trabajos, preliminarmente se presentan elementos para el análisis, resaltando entre ellos, los constantes desalojos y reubicaciones del comercio informal en las calles, actividad cada vez más abundante en términos de la población ocupada, así como las presiones de desplazamiento que están expresando los vecinos de los desarrollos analizados por los cambios en el uso del suelo, de habitacional popular a comercio departamental, oficinas y habitacional residencial para altos ingresos. En varias ocasiones se ha prohibido el comercio informal dentro del Perímetro A

\footnotetext{
4 Varios autores señalan que más del $60 \%$ de la población metropolitana de la Ciudad de México vive en barrios precarios, en gran parte autoconstruidos. Para una perspectiva crítica sobre las políticas de vivienda social, ver Martha Schteingart, Emilio Pradilla, Manuel Perló, Beatriz García, Claudia Puebla, entre otros autores.
} 
del Centro Histórico 5 y se han empleado diversas formas de desalojo; por una parte, el gobierno local recurrió a la prohibición del comercio en vía pública en 1993 en ese perímetro y también se implementó el Programa de Comercio Popular en 1994, logrando la reubicación negociada del ambulantaje en 27 plazas comerciales dentro del mismo Perímetro A. Sin embargo, en el contexto de la crisis económica y política, las organizaciones de comercio informal adquirieron gran fuerza, asociada con acciones corporativistas, como el manejo clientelar partidista. Su incremento numérico, el encarecimiento de las cuotas y subarriendos, entre otras razones, motivaron su desbordamiento de las plazas comerciales donde se les reubicó y retornaron a las calles, rentando los locales o empleándolos como bodegas. Se han sucedido numerosos acuerdos con jefes de gobierno del Distrito Federal de diversos partidos políticos en consonancia con los intereses de inversionistas y comerciantes interesados en la remodelación, para "liberar" del "comercio popular" a las áreas revitalizadas, negociando que solo en la época navideña se permita el comercio en ciertas calles y horarios. Por ejemplo, en La Alameda, el primer parque público de la ciudad, a partir de su remodelación en 2012 ya no se permiten las romerías populares en ningún período del año; asimismo se eliminó el comercio ambulante sobre la avenida Juárez y calles transversales (Figura $N^{\circ} 2$ ). Se busca invisibilizar a los pobres y despejarlos de las edificaciones nuevas y remodeladas alrededor del emblemático parque, considerando que el ambulantaje reduce el valor de las rentas urbanas. Procesos de desplazamiento han ocurrido de manera directa en Santa Fe (entrevistas realizadas en 2011, en Olivera, 2013b), así como en las poco claras expropiaciones para la construcción de la Supervía Poniente (Barros, C. La Jornada, 28 junio 2013), e indirectamente a partir del encarecimiento del suelo con los megaproyectos enclavados en barrios deteriorados susceptibles de un alto grado de cambio de usos del suelo por la normatividad urbana permisible y laxa.

\footnotetext{
5 Concentra los edificios históricos prehispánicos y hasta la Guerra de Independencia en $3.2 \mathrm{~km}^{2}$ rodeado por el perímetro $\mathrm{B}$, con edificaciones posteriores catalogadas hasta el XIX, comprende un área de $5.9 \mathrm{~km}^{2}$.
}

Esto está sucediendo en las localidades conurbadas con los cambios de uso de vivienda popular, baldíos, barrancas y ejidos alrededor de los proyectos Santa Fe, Interlomas, así como vivienda popular y plantas industriales fordistas mezcladas con pequeñas industrias en Nuevo Polanco, en el oeste de la ciudad. Donde actualmente se están extendiendo los usos mixtos, habitacional residencial vertical, condominios cerrados, mezclada con servicios profesionales, edificios de grandes corporativos y comercio de lujo y departamental (Olivera, 2013).

\section{La neoliberalización y la estrategia de revalorización del suelo a través de los megaproyectos}

El neoliberalismo es una estrategia de consolidación del capital financiero global para recomponer las condiciones de acumulación, esto implica la activa movilización del poder del Estado. En 1982 en México toma el poder político la fracción "tecnócrata", desde donde se legitimó la ideología del mercado como la "única vía" para el desarrollo, implementándose políticas neoliberales. Desde entonces, se ha reestructurado el Estado y se han impulsado un conjunto de reformas políticas, económicas, urbanas para permitir las nuevas formas de acumulación de capital, posibilitar el libre flujo de capitales en escala global y garantizar el libre mercado en su más amplia expresión (Olivera, 2014). En particular, en la Ciudad de México la estrategia neoliberal materializó la reestructuración del Estado y los intereses privados locales con la participación de grupos financieros del país y del exterior a través de la "Reforma de Estado" y la "Reforma urbana", haciendo de la ciudad un espacio atractivo para el capital global y acelerando la especialización de la ciudad en servicios productivos, circulando libremente los capitales hacia el sector financiero e inmobiliario, lo que repercutió en la progresiva polarización social y en la privatización de espacios centrales a través de procesos asociados a la gentrificación (Olivera, 2013). Este conjunto de reformas estructurales adquieren operatividad a través de las llamadas "modernización, descentralización o democratización del Estado"; la 
eficientización de la administración pública; con objetivos y agendas de competitividad y sustentabilidad; a través de la gobernanza y transparencia con la adopción de tecnologías informáticas y portales abiertos, diseñados desde la Organización para la Cooperación y el Desarrollo Económico (OCDE) y otros organismos internacionales. Se delega lo público a lo privado, se privatizan bienes y servicios públicos para garantizar los negocios privados, empleando estrategias de control para mantener el orden social, sea a través del monopolio de la fuerza pública, los medios y las instancias de gobierno.

En México la adopción de la racionalidad de mercado priorizó la competitividad de la economía a través de la creación de condiciones adecuadas para atraer negocios e inversiones locales y foráneas y alcanzar el desarrollo y la filtración de los beneficios económicos hacia abajo, a todas las capas sociales. La gestión público- privada neoliberal configuró instrumentos de política pública acompañados de inversión para incentivar las acciones privadas en varios procesos de gentrificación en la Ciudad de México. Particularmente se favoreció a Carso, propiedad del Ing. Carlos Slim, el cual constituye un grupo financiero con negocios en numerosos segmentos de la industria, comercio y servicios, cuyas empresas de telecomunicaciones, bancarias, comercio departamental, de alimentos, construcción e inmobiliarias se han beneficiado con estas políticas. Una de las más trascendentes fue el Bando 26, al acelerar la actividad inmobiliaria con los nuevos usos señalados transformó la morfología de la ciudad interior, los barrios residenciales eminentemente horizontales, se convirtieron en centros comerciales, corredores de usos mixtos e intensivos, cuya edificación se verticalizó, particularmente en las cuatro delegaciones centrales, con excepción de los inmuebles dentro de las "Áreas de Conservación Patrimonial", fundamentalmente

\footnotetext{
6 Ordenamiento publicado por el jefe de gobierno el 7 de diciembre de 2000 y vigente hasta 2006, pretendía reorientar el crecimiento urbano hacia las cuatro delegaciones centrales, construir vivienda "para la gente humilde" y restringir la construcción en nueve delegaciones, conservando el valor ecológico (ver Tamayo, 2007).
}

en el centro histórico, donde se permitieron diversos usos y su mezcla, pero sin modificaciones arquitectónicas. Sin embargo se añadió una reglamentación para transferir a predios aledaños el valor de interés inmobiliario a través de la normatividad denominada "Sistema de Transferencia de Potencialidad de Desarrollo", 7 establecida en la Ley de Desarrollo Urbano, con lo cual se promueven intensidades muy altas en usos del suelo de vivienda y actividades comerciales y de servicios en sitios aledaños (Olivera, 2013b).

Para revertir la crisis por la reestructuración económica, desde la década de 1990 la gestión urbana se orientó hacia la "ciudad competitiva", movilizando las inversiones a través de los negocios para las empresas y el desarrollo inmobiliario, abarcando un conjunto diverso de políticas e incentivos para el desarrollo de nuevos enclaves de servicios globales, la construcción de megaproyectos con usos mixtos, la edificación de centros comerciales, vivienda residencial y en menor medida social. Asimismo, se impulsó el turismo cultural, urbano, ecológico y con ello la turistificación de enclaves urbanos que se distinguen por su patrimonio histórico inmueble, su paisaje cultural, sus atributos naturales. Sin embargo, se trata de un desarrollo inmobiliario que profundiza la histórica segregación socioespacial residencial, de clase, de la Ciudad de México porque el conjunto de grandes emprendimientos urbanos ha conducido al encarecimiento de las rentas urbanas y al desplazamiento directo e indirecto de la población de bajos ingresos, quien ha tenido que emigrar a periferias urbanas distantes o a áreas rurales sin servicios ni infraestructuras, para alojarse en una vivienda y suelo barato.

A diferencia de otros países latinoamericanos que han ido abandonando las directrices más excluyentes del modelo neoliberal, en México esta perspectiva de liberalización económica se profundiza. En medio de una crisis económica y política, en el otoño de 2013 las Cámaras de Diputados y Senadores del poder legislativo nacional discuten las "Reformas educativa y energética", la primera

\footnotetext{
7 Este STPD se creó expresamente para el Centro Histórico en 1988.
} 
desconoce los derechos laborales y empobrece la calidad de la educación y la última para privatizar completamente las empresas de Petróleos Mexicanos. Esta incondicionalidad de las elites y del gobierno mexicano a los intereses privados es socialmente rechazada en las calles de la ciudad. Infortunadamente, sectores de gobierno del Distrito Federal a nombre de la "izquierda moderna" apoyan estas reformas, en aras de la "competitividad económica" y del "desarrollo sustentable". No obstante que a partir de las reformas neoliberales en los ochentas la Ciudad de México sufrió un proceso de desindustrialización absoluta y relativa ${ }^{8}$ y el incremento de los servicios principalmente dentro de la informalidad $^{9}$.

Las políticas urbanas en la Ciudad de México se reestructuraron en términos de la asociación histórica del poder económico con el poder público y, asimismo, por la delimitación de los poderes federal y de la ciudad a partir de los cambios que trajo la liberalización económica de 1983. Producto de las crisis económicas y sociales asociadas con el ejercicio del poder político representado por el grupo del oficial Partido Revolucionario Institucional (PRI) promotor de la implantación neoliberal, en la conciencia de las mayorías residentes en la Ciudad de México se le responsabilizó de las repercusiones sociales negativas. En 1997, después de la reforma política federal para el Distrito Federal, se dio la conjunción de fuerzas de izquierda dentro y fuera del Partido de la Revolución Democrática (PRD) para la candidatura de Cuauhtémoc Cárdenas como jefe de gobierno (1997-1999), quien obtuvo 48,11\% de los votos totales, y el PRD ganó 38 de los 40 distritos electorales, el PAN los 2 restantes, 0 para el PRI.

Durante este primer gobierno democrático de la ciudad se instauró la consulta ciudadana, y disminuyeron notablemente los

8 Las ramas industriales atrasadas entraron en quiebra, otras se han relocalizado, entre ellas la química, automotriz, la Ciudad de México se especializa en partes, pero las plantas se relocalizaron hacia la frontera.

9 Se calcula que alrededor del $60 \%$ de la mano de obra en la Ciudad de México es informal (INEGI, 2011). conflictos entre el poder público y el poder económico, se lograron consensos para desarrollar tareas públicas como seguridad, educación y salud y se desarrollaron los negocios privados con algunas limitaciones para giros negros. En el segundo gobierno de la ciudad (2000-2006) obtuvo el triunfo Andrés Manuel López Obrador, con el 34,5\% de los votos, el PAN-Verde 33,4\% y el PRI 22,6\%. López Obrador surgió de las luchas sociales dentro del espectro centro- izquierda; al mando del poder público en el Distrito Federal aplicó, por una parte, una política social básica para el apoyo a sectores vulnerables: ancianos, mujeres jefes de familia, discapacitados, lo que tuvo una amplia aceptación y elevó su capital político; por otro lado, emitió las controvertidas políticas que favorecieron al desarrollo inmobiliario y empresarial, impulsando numerosos megaproyectos en la Ciudad de México. El tercer gobierno de la ciudad, encabezado por Marcelo Ebrard Casaubon (2006- 2012), profundizó la orientación neoliberal; el cual, junto con Manuel Mancera (2012-2018), cuarto jefe de gobierno, no provienen de las filas de la izquierda mexicana, el primero se afilió al Partido de la Revolución Democrática (PRD) poco antes de asumir el cargo y el segundo no tiene filiación política. No obstante, Ebrard ganó la Jefatura de gobierno con el $46,37 \%$ de los votos para el PRD, el PAN alcanzó $27,26 \%$ y el PRI- Verde $21,59 \%$. Finalmente, Mancera obtuvo el $63,56 \%$ de los votos en 2012, el PRI $19,76 \%$ y PAN $13,59 \%$ (para ampliar información electoral: www.iedf.org.mx). Estas cifras paradójicamente señalan la elevación de la legitimidad de los gobernantes cuando más se neoliberalizan las prácticas excluyentes en los espacios de la ciudad con la valorización de los grandes proyectos neoliberales en los barrios elegidos, en detrimento de la distribución equitativa de los recursos públicos.

\section{Proyectos neoliberales en barrios paradigmáticos de la Ciudad de México}

En otros trabajos se han presentado los antecedentes de los procesos de la gentrificación en el Centro Histórico (Delgadillo, 2011, 2012), Santa Fe y norte de Polanco articulados con la neoliberalización de la ciudad de México y con la periodización y condi- 
ciones de la funcionalidad y diferenciación social (Olivera, 2013). Considerando que estas estrategias de gestión urbana neoliberal resultaron exitosas desde la perspectiva de los grandes emprendimientos inmobiliarios, encontramos que se han ampliado y reproducido en otros barrios de la ciudad interior. Con las reformas neoliberales financiera y urbana, desde la década de 1990 el sector inmobiliario tuvo un gran auge debido al profuso otorgamiento de créditos hipotecarios de vivienda para estratos medios y altos, y para las empresas contratantes comerciales y de servicios avanzados; parecía confirmarse que la apertura hacia el mercado externo traería inversiones que beneficiarían a todos los sectores sociales en el país. Numerosas empresas constructoras participaron en las licitaciones públicas para la construcción de vivienda social y de infraestructuras varias. Sin embargo, la situación resultó transitoria, debido a que el gobierno federal neoliberal había convertido a México en importante receptor de las nuevas y más volátiles formas de inversión entre los países Ilamados "emergentes" o de "nueva industrialización". La salida de capitales especulativos minó las reservas de divisas, y para revertir la crisis se utilizó la macrodevaluación y las medidas de contracción monetaria y fiscal, lo que desencadenó la crisis de diciembre de 1994 financiera, productiva y social.

No obstante, en el corto período 19891994 se incrementaron los grandes proyectos urbanísticos del comercio moderno -departamentales y tiendas de autoservicios- en conflicto con el comercio tradicional de pequeña escala frente a las grandes cadenas comerciales y franquicias. Fue un breve período de inversión de capitales en la ciudad, pero con repercusiones a largo plazo: desde la remodelación del Centro Histórico y la gestión del centro corporativo Santa Fe, hasta la difusión urbana a través de grandes desarrollos habitacionales metropolitanos y la extensión de redes comerciales de hipermercados, lo que ha fomentado la renovación y rearticulación de los sistemas de vialidades rápidas. En este período también se iniciaron las formas de gestión urbana empresarialista (ver Harvey, 1989) en la cual el sector privado asume responsabilidades antes de atribución pública: en Santa Fe el gobierno cedió la administración de los servicios públicos dentro del centro corporativo a la Asociación de colonos, representante de facto de las empresas, en 2012 retornó a la administración pública, bajo la figura de "Autoridad" pública.

En la década de 2000, ante un nuevo período de auge y con base en la gestión público-privada se impulsaron nuevas inversiones de proyectos asociados a los anteriores, entre ellos destacan las grandes obras de infraestructura vial y de transporte por la necesidad de movilizar a la población metropolitana demandante y también a escala regional, lo cual significó la ampliación y conclusión selectiva ${ }^{10}$ de los anillos viales que unen las salidas de carreteras a las ciudades de la megalópolis. Estas obras se retrasaron por las numerosas protestas de población urbana y rural afectada, así como ecologistas y organizaciones sociales. Así, se amplió la carretera de cuota a Toluca, a escala intrametropolitana estas vialidades articularon los principales nodos de comercio y servicios a través de circuitos internos de acceso controlado -segundo piso Periférico, circuito Bicentenario-y con la estructuración de vialidades primarias ortogonales, se desarrollaron los segundos pisos en el Periférico poniente y se promovió la Supervía. Estas obras han sido apoyadas y demandadas por los sectores empresariales, esta última específicamente por representantes de Santa Fe, a partir del colapso de la movilidad en la zona poniente de la ciudad de México por la estructura desarticulada de los desarrollos corporativos privados en la zona de morrenas con extensos abarrancamientos y ocupaciones extensivas, irregulares y sin servicios alrededor de Santa Fe. La estrategia del gobierno de Ebrard fue justificar este proyecto haciéndolo parecer necesario en las discusiones entre gobierno y empresarios, argumentando la productividad del centro corporativo, dejando de lado los costos sociales para los sectores populares y aun medios. A pesar de las críticas fundamentadas de ecologistas, residentes, organizaciones sociales y del responsable de Derechos Humanos del

\footnotetext{
10 El Anillo Periférico, vialidad confinada de alta velocidad, no se ha concluido en el suroriente de la ciudad: al pasar la Av. Tláhuac comienzan los semáforos y moderadores de velocidad.
} 
Distrito Federal se edificó la obra, incluyendo violentos desalojos ${ }^{11}$.

En el Distrito Federal durante el período 2001 a 2005 se ejercieron 152.406 créditos para vivienda social nueva terminada, la mayor parte para mejoramiento de vivienda; de los cuales el 36\% los otorgó Infonavit y $47,8 \%$ el Instituto de Vivienda $\left(\right.$ INVI) ${ }^{12}$. Aprovechando la emisión del "Bando 2", y la inercia desatada, los constructores privados han edificado vivienda vertical en las delegaciones centrales, particularmente Benito Juárez, Miguel Hidalgo y el sur de Cuauhtémoc, compitiendo por el escaso suelo entre ellas y los demandantes pobres, y encareciendo los bienes inmuebles. La vivienda unifamiliar decreció, ante el fuerte proceso de demolición, y la edificación de vivienda en departamento se incrementó en $16,9 \%$, pasó de 259.690 en 2000 a 303, 463 en 2005 en las cuatro delegaciones, incluyendo a Venustiano Carranza. La vivienda en vecindad declinó en $-11,7 \%$ y en azotea $-27,4 \%$ en el mismo período (Esquivel, 2007). La nueva población residente supera en ingreso a los residentes anteriores, considerando los costos de las promociones de vivienda social, en 2000 el precio promedio era de $\$ 43.200$ dólares y en 2008 se elevó a más de \$157.000 dólares con las promociones privadas; el precio es cuatro veces más alto que en la segunda ciudad más cara del país (Benlliure, 2008). Este encarecimiento de la vivienda se deriva de las políticas y programas aplicados de acuerdo con la zonificación, tipos de usos, intensidades, así como infraestructuras condicionadas a estándares de calidad, particular-

\footnotetext{
11 La Gaceta Oficial del Gobierno del Distrito Federal, 11 de diciembre 2009 emitió la "Declaratoria de necesidad para el otorgamiento de una concesión para explotar y administrar una vía de comunicación urbana de peaje" y el Diario Oficial de la Federación (DOF) 22 de marzo del 2010 la declaró de "utilidad pública".

12 El INVI es un organismo público descentralizado del gobierno del Distrito Federal, con personalidad jurídica y patrimonio propio. Fue creado para atender la necesidad de vivienda de la población residente, principalmente de bajos recursos económicos, a través del otorgamiento de créditos de interés social. El Infonavit es un organismo federal que recauda las cuotas patronales conformadas por el 5\% del salario de los trabajadores, con el propósito de obtener crédito para vivienda o el reembolso del ahorro.
}

mente la Norma 26 permite la elevación de precios e intensidades en el Centro Histórico. En este contexto de competencia por el suelo urbanizado, la población derechohabiente del Instituto del Fondo Nacional de Vivienda para los Trabajadores (INFONAVIT) del DF satisface su necesidad de vivienda social en los municipios vecinos, donde el suelo es más barato: el $75 \%$ de los créditos otorgados por ese instituto a sus derechohabientes en el Distrito Federal se ejercieron en el Estado de México (Morteo, 2005). En ese sentido, el Distrito Federal es una entidad expulsora, particularmente las delegaciones centrales; en el período censal más reciente, entre 2005 y 2010 , emigraron 130.000 personas $^{13}$.

Centro Histórico, un recuento de las fases de los programas de remodelación y revitalización

Por decreto presidencial en 1980 se definió el perímetro del Centro Histórico (con 9,1 Km², 668 manzanas y 9.263 predios), por la concentración de monumentos históricos y su función simbólica (Figura $N^{\circ} 1$ ). Su centralidad metropolitana se deriva de su gran accesibilidad y de las funciones políticas y simbólicas que desempeña: sede del gobierno nacional, comercio especializado, servicios urbanos y equipamientos regionales, metropolitanos y nacionales. Este territorio, que a mediados del siglo XIX constituía toda la ciudad, se caracteriza por los fuertes contrastes sociales: 1. Los barrios del norte y del oriente habitados por familias de bajos ingresos, una gran actividad comercial formal e informal, así como un acusado deterioro físico, allí se reconstruyeron más de 13 mil viviendas después de los sismos de 1985. Hasta 2007 no había programas de recuperación del patrimonio edificado. 2. La zona centro y los barrios del sur y poniente son sede del comercio moderno mezclado con servicios, varios inmuebles han sido restaurados, las plantas bajas se encuentran ocupadas por bancos, oficinas, comercios y museos para clientes de medianos ingresos, las plantas altas están vacías o subutilizadas. Se trata de la zona más

\footnotetext{
13 En 2010 las cuatro delegaciones centrales contaron con 1.721.137 habitantes (INEGI, Censo de Población 2010 y Conteo 2005, Aguascalientes).
} 
visitada por los turistas, sin embargo la más despoblada, donde se encuentran la mayoría de las inversiones de Slim y donde población de mayores ingresos reside o tienen despachos. Las diferencias socioeconómicas del Centro Histórico $(\mathrm{CH})$ son enormes: en 2000 el $52 \%$ de la población residente percibía ingresos de hasta 2 veces el salario mínimo, con las remodelaciones los nuevos residentes forman parte de los deciles más altos (INEGI, 2012).

Las políticas de renovación del Centro Histórico han estado presentes a lo largo de su historia. Sin embargo, el interés en la mercantilización del patrimonio arquitectónico se inicia con los gobiernos neoliberales, en la década de 1990, se emplean los eslóganes de Rescate, Revitalización, Rehabilitación, aun Recuperación del Centro Histórico para denominar programas, con una carga simbólica que busca introducir la transformación necesaria e inminente haciéndola atractiva para el sector privado, las finanzas y legitimidad del gobierno. Así, El "Fideicomiso del Centro Histórico de la Ciudad de México" se estableció en 1990 como instancia público privada para la planeación, la coordinación y la aplicación del Programa de Rehabilitación, el que inició con alrededor de 131.000 dólares para la creación de infraestructura, restauración de fachadas, dotación de mobiliario, pavimentación y renovación de espacios públicos. En el Programa de revitalización del Centro Histórico 2006, participaron los gobiernos federal y del Distrito Federal y el Ing. Slim. Para ello se creó el Consejo Consultivo para el Rescate del Centro Histórico de la ciudad de México en 2001 y un Comité Ejecutivo de dicho consejo consultivo, ambos encabezados por el magnate mexicano. Slim creó a su vez la Fundación Centro Histórico, A.C. en 2002 y la inmobiliaria Centro Histórico de la Ciudad de México S.A., de C.V., una para implementar programas sociales para las personas que viven y trabajan en la zona centro de la capital, y la otra para comprar y rehabilitar inmuebles. Entre 1986 y 2013 el grupo Carso invirtió \$1.800.000 en diversos negocios inmobiliarios (Cuadro $N^{\circ} 1$ y $N^{\circ} 2$ ). En el año 2009 por adquisición de inmuebles, materiales y equipo del grupo Carso, las inversiones sumaron 4.500.000 de dólares (Estados financieros del Grupo Financiero Carso, 2010). Solo entre 2002 y 2004 invirtió 31.000.000 de dólares en la compra de 31 inmuebles en el Centro Histórico (Delgadillo, 2011).

\section{Cuadro $\mathrm{N}^{\circ} 1$}

Principales megaproyectos inmobiliarios urbanos del Grupo Carso en la Zona Metropolitana de la Ciudad de México, 1986-2013

\begin{tabular}{|c|c|c|c|c|c|}
\hline \multicolumn{6}{|c|}{ Plazas y centros comerciales } \\
\hline Plaza & Uso anterior & $\begin{array}{l}\text { Delegación/ } \\
\text { Municipio }\end{array}$ & $\begin{array}{l}\text { Superficie } \\
\mathrm{m}^{2}\end{array}$ & $\begin{array}{l}\text { Inversión } \\
\text { Dólares }{ }^{1}\end{array}$ & $\begin{array}{l}\text { Año de } \\
\text { inicio }\end{array}$ \\
\hline Inbursa & $\begin{array}{l}\text { Fábrica de papel y zona } \\
\text { arqueológica de Cuicuilco }\end{array}$ & Tlalpan & 190.000 & 540 & 1986 \\
\hline Loreto & Fábrica de cigarros & Álvaro Obregón & 38.000 & 104 & 1993 \\
\hline Plaza Carso & $\begin{array}{l}\text { Reconversión de plantas de } \\
\text { Ilantas y vidrio }\end{array}$ & Miguel Hidalgo & 120.000 & 2.200 & 008 \\
\hline $\begin{array}{l}\text { Mexipuerto } \\
\text { Ciudad Azteca }\end{array}$ & $\begin{array}{l}\text { Cercanía al proyecto can- } \\
\text { celado del aeropuerto de } \\
\text { Atenco }\end{array}$ & $\begin{array}{l}\text { Ecatepec, Estado } \\
\text { de México }\end{array}$ & 800 & 5.404 & 2009 \\
\hline $\begin{array}{l}\text { CETRAM² El }^{2} \\
\text { Rosario }\end{array}$ & Sitio de comercio informal & Azcapotzalco & 62.000 & 40 & 2011 \\
\hline $\begin{array}{l}\text { Ciudad Jardín } \\
\text { Bicentenario }\end{array}$ & $\begin{array}{l}\text { Bordo Xochiaca, canal } \\
\text { de aguas negras y antes } \\
\text { basurero }\end{array}$ & $\begin{array}{l}\text { Nezahualcóyotl } \\
\text { Estado de México }\end{array}$ & 1.500 .000 & 480 & 2012 \\
\hline
\end{tabular}


Continuación Cuadro Nº 1

\begin{tabular}{|c|c|c|c|c|c|}
\hline \multicolumn{6}{|c|}{ Plazas y centros comerciales } \\
\hline Plaza & Uso anterior & $\begin{array}{l}\text { Delegación/ } \\
\text { Municipio }\end{array}$ & $\begin{array}{c}\text { Superficie } \\
\mathrm{m}^{2}\end{array}$ & $\begin{array}{l}\text { Inversión } \\
\text { Dólares }{ }^{1}\end{array}$ & $\begin{array}{l}\text { Año de } \\
\text { inicio }\end{array}$ \\
\hline $\begin{array}{l}\text { Plaza Capuchi- } \\
\text { nas }\end{array}$ & Antiguo convento & $\begin{array}{l}\text { Cuauhtémoc } \\
\text { Centro Histórico- } \\
\text { Venustiano } \\
\text { Carranza }\end{array}$ & 16.000 & 65 & 2013 \\
\hline \multicolumn{6}{|l|}{ Vivienda } \\
\hline $\begin{array}{l}\text { Residencial } \\
\text { Carso Alameda }\end{array}$ & Hotel Bamer & $\begin{array}{l}\text { Cuauhtémoc } \\
\text { Centro Histórico- } \\
\text { Alameda }\end{array}$ & $\begin{array}{r}778 \mathrm{~m}^{2} \\
9.990 \mathrm{~m}^{2} \mathrm{de} \\
\text { construcción }\end{array}$ & 23 & 2013 \\
\hline Dolores & Remodelación edificio & $\begin{array}{l}\text { Cuauhtémoc } \\
\text { Centro Histórico- } \\
\text { Alameda sur }\end{array}$ & $\begin{array}{r}600 \mathrm{~m}^{2} \\
6.000 \mathrm{~m}^{2} \mathrm{de} \\
\text { construcción }\end{array}$ & 23 & 2015 \\
\hline \multicolumn{6}{|l|}{ Oficinas Públicas } \\
\hline $\begin{array}{l}\text { Secretaría de } \\
\text { Relaciones } \\
\text { Exteriores }\end{array}$ & $\begin{array}{l}\text { Habitación, servicios y co- } \\
\text { mercios, en altura dañados } \\
\text { por los sismos de } 1985\end{array}$ & $\begin{array}{c}\text { Cuauhtémoc } \\
\text { Centro Histórico- } \\
\text { Alameda }\end{array}$ & n.d. & 6.948 & 2005 \\
\hline $\begin{array}{l}\text { Centro de Co- } \\
\text { municaciones, } \\
\text { Cómputo, Con- } \\
\text { trol y Comando } \\
\text { (C-4) }\end{array}$ & $\begin{array}{l}\text { Modernización tecnológica } \\
\text { en oficinas de la Secretaría } \\
\text { de Seguridad Pública del } \\
\text { Distrito Federal }\end{array}$ & $\begin{array}{l}\text { Cuauhtémoc } \\
\text { Centro Histórico- } \\
\text { Plaza de la } \\
\text { Constitución }\end{array}$ & n.d. & 1.544 & 2011 \\
\hline
\end{tabular}

Notas: 1. Millones de dólares. 2. Centro de Transferencia Modal

Fuente: Patricia Olivera, elaboración propia con base en Carso, 100 obras impulsoras del Desarrollo, México, Real State Market \& Lifestyle, 90, 2013.

El grupo Carso ha expresado que en el Centro Histórico de la Ciudad de México "la plusvalía de la zona se ha triplicado en 10 años por la presencia de hoteles, cafés, clubes, comercios" (Carso, Revitalización del Centro Histórico, 2013:112). Este interés en el espacio central de la ciudad emblemática del país es proporcional al incremento de las rentas potenciales, primordialmente derivadas del turismo y los negocios asociados, dado que se tiene una población flotante muy alta, estimada en más de un millón de personas diarias. Se trata de gente que visita, trabaja, compra, pernocta, acude a sitios lúdicos y de consumo de bienes culturales. Este promotor justifica la producción de nuevas actividades de comercio y servicios porque "la población así lo demanda y reclama"..."lo más impor- tante es crear valor sobre esas zonas" (Ibid). Las edificaciones restauradas señaladas en el Cuadro $\mathrm{N}^{\circ} 2$ tuvieron el apoyo público local, para fomentar la función comercial y turística del Centro Histórico: numerosos inmuebles históricos son actualmente museos privados y públicos, algunos administrados por la UNAM y otras universidades públicas. La derrama consignada en el Cuadro $\mathrm{N}^{\circ} 2$ es significativa del interés mercantil, además del social.

El Plan Integral de Manejo del Centro Histórico 2011-2016 prevé la actuación sobre el patrimonio edificado de manera secuencial en los barrios del Perímetro A y B, norte y oriente, apoyándose en la Autoridad del Centro Histórico $(\mathrm{ACH}$, en 2007) y como parte 
Cuadro $\mathrm{N}^{\circ} 2$

Revitalización del Centro Histórico 2001- 2012

\begin{tabular}{|l|r|l|}
\hline Programa & Unidades & \multicolumn{1}{|c|}{ Acciones } \\
\hline Vivienda & 1.000 & Más de 100 edificios restaurados \\
Plazas comerciales & 47 & Inmuebles restaurados \\
Comercio en vía pública & 19.500 & Reubicados \\
Cultura y turismo & 28 & $\begin{array}{l}\text { Recaudación de 3.200.000 dólares anuales } \\
\text { Rehabilitación } \\
\text { Plazas y jardines }\end{array}$ \\
Infraestructura & Calles Perímetro A & $\begin{array}{l}\text { Pavimentación, sustitución redes agua, drenaje, } \\
\text { energía eléctrica y fibra óptica } \\
\text { Inversión Total }\end{array}$ \\
\hline
\end{tabular}

Fuente: Patricia Olivera, elaboración propia en base a Carso (2013).

de la estructura operativa la Intendencia del Centro Histórico (2008). En este período se restauraron algunos inmuebles, se introdujo la línea 4 del transporte colectivo Metrobús, que vincula el Centro Histórico con el Aeropuerto Internacional, se estableció la política de espacio público limitado por el propósito convivencial, se habilitaron circuitos para ciclistas en avenidas y carriles confinados, corredores peatonales y plazas, las más importantes Madero, La Plaza de la Constitución, se alternaron actividades lúdicas: playas artificiales, pistas de patinaje, conciertos gratuitos, se peatonalizó y embelleció el emblemático Monumento a la Revolución en la plaza del mismo nombre, y continuó la restauración de edificaciones y monumentos en Avenida Juárez y La Alameda ${ }^{14}$. Se invirtió en programas de seguridad, con cámaras de vigilancia, policía adicional, inteligencia, protección civil, infraestructura tecnológica con fibra óptica, todo ello a través de la gestión público-privada, a través de la $\mathrm{ACH}$ como órgano coordinador de los agentes sociales participantes, entre ellos dependencias de los gobiernos federal y local, instituciones académicas, inversionistas y actores del Consejo Consultivo para el Rescate del Centro Histórico (Jefatura de Gobierno, 2011). En 2007 se

\footnotetext{
${ }^{14}$ Disponible en línea http://www.autoridadcentrohistorico.df.gob.mx/noticias/articulos/plan_de_manejo. pdf
}

acordó la reubicación del comercio informal, alrededor de 15 mil ambulantes de 192 manzanas y 87 calles, se trataron de congregar en 36 plazas comerciales ${ }^{15}$. El Plan Integral conjuga las acciones y negociaciones anteriores con el propósito esencial de la dinamización de la función turística del Centro Histórico, después del impuesto catastral es una de las principales fuentes de ingreso público de la ciudad (Cuadro N²). En el Plan de 2011 se mantiene el interés en el proyecto de revitalización particularmente en el Perímetro A y se eligen zonas de actuación con acciones concretas gestionadas por la promoción públicoprivada, las principales propuestas consisten en fortalecer el uso habitacional y la mezcla de usos, incluyendo edificios abandonados, inmuebles catalogados y espacios públicos, cuya fuente de inversión inmobiliaria es privada.

Actualmente, la inmobiliaria del grupo Carso ha remodelado más de 100 edificaciones en este perímetro patrimonial de la ciudad (Cuadro $\mathrm{N}^{\circ} 1$ y No 2). En 2006, la mayoría de sus inmuebles renovados funcio-

\footnotetext{
15 La reubicación del comercio informal se realizó en el mismo $\mathrm{CH}$, producto de negociaciones del gobierno del DF con las organizaciones, algunas con carácter clientelar. Lo cual puede considerarse parte de la resistencia a la gentrificación por actividades comerciales.
} 


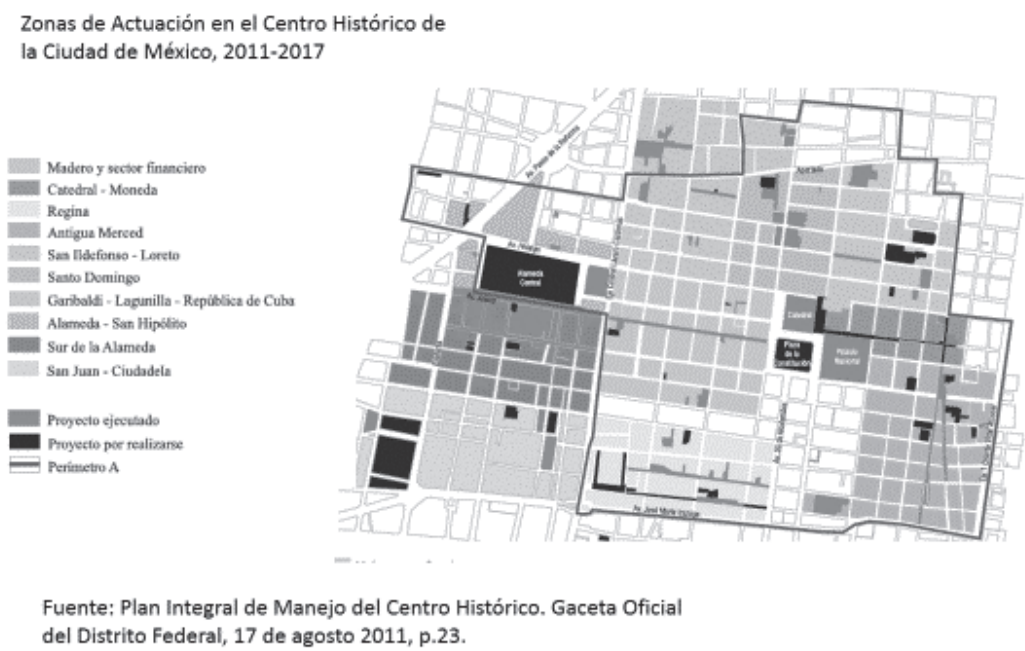

Fuente: Plan Integral de Manejo del Centro Histórico. Gaceta oficial del Distrito Federal, 17 de agosto de 2011, p.23.

naron como oficinas corporativas de Telmex, call centers, tiendas minoristas, mayoristas y plazas comerciales y departamentales. En la Figura $\mathrm{N}^{\circ} 2$ se muestran dos edificios en la manzana intermedia, ambos han sido remodelados y tienen usos corporativos, a la derecha comercio departamental: tienda de la cadena Sears, y a la izquierda, uno de los edificios de telecomunicaciones de Telmex. A la derecha, edificio de la librería Porrúa, una de las más antiguas de la ciudad, tiene un uso de vivienda, actualmente sin ocupación evidente. Todos ellos propiedad del Ing. Carlos Slim. A la izquierda la Torre Latinoamericana, donde este inversionista es dueño de varios pisos. En relación con los proyectos de vivienda, la venta de estudios tipo loft y departamentos remodelados desde 60 a $225 \mathrm{~m}^{2}$ oscilaron entre 70.000 y 300.000 dólares y la mayoría se ubicaban en la zona comercial y financiera: las calles de Madero, 5 de mayo, 16 de Septiembre, Venustiano Carranza, Isabel la Católica, Bolívar, Uruguay, Mesones, Salvador, San Jerónimo, Donceles, Regina, Vizcaínas, avenida Juárez, Revillagigedo y Luis Moya (P. Olivera, entrevista con funcionaria de la Inmobiliaria Centro Histórico, S.A., octubre 2006), posteriormente adquirieron otros inmuebles, entre ellos el Hotel
Bamer (ubicado en avenida Juárez) donde se inició en 2010 el desarrollo de 100 departamentos de lujo de 75 metros cuadrados con un costo promedio de 151.000 dólares cada uno (Real Estate Market and Lifestyle, información de mayo 2011). Asimismo, los hoteles Virreyes y Señorial se transformaron en hostal y en viviendas para estudiantes, respectivamente.

Con base en información de septiembre de 2013, dentro de la zona financiera y turística, el precio de venta de departamentos remodelados en la calle Uruguay, con $50 \mathrm{~m}^{2}$ tiene valor de 115.000 dólares; en Mesones, los departamentos en promedio de $97 \mathrm{~m}^{2}$ ascienden a 135.000 dólares; y en Paseo de la Reforma dentro del $\mathrm{CH}$ con $98 \mathrm{~m}^{2}$ cuestan 340.000 dólares (Inmobiliaria Garlo, septiembre 2013). Cabe destacar que los precios oscilan su ritmo debido a la crisis del sector inmobiliario en México de 2008 (ver revistas Real Estate Market and Lifestyle, 2013). Con la revalorización de los inmuebles remodelados, particularmente aquellos con rentas congeladas hoy abolidas, se presentó la apropiación de la rent gap, con una brecha muy alta, constatada a partir de la elevación de los precios de inmuebles antes señalados, tanto 
Figura $\mathrm{N}^{\circ} 2$

Centro Histórico, barrio La Alameda, sobre Avenida Juárez, al sur del Parque Urbano La Alameda Central

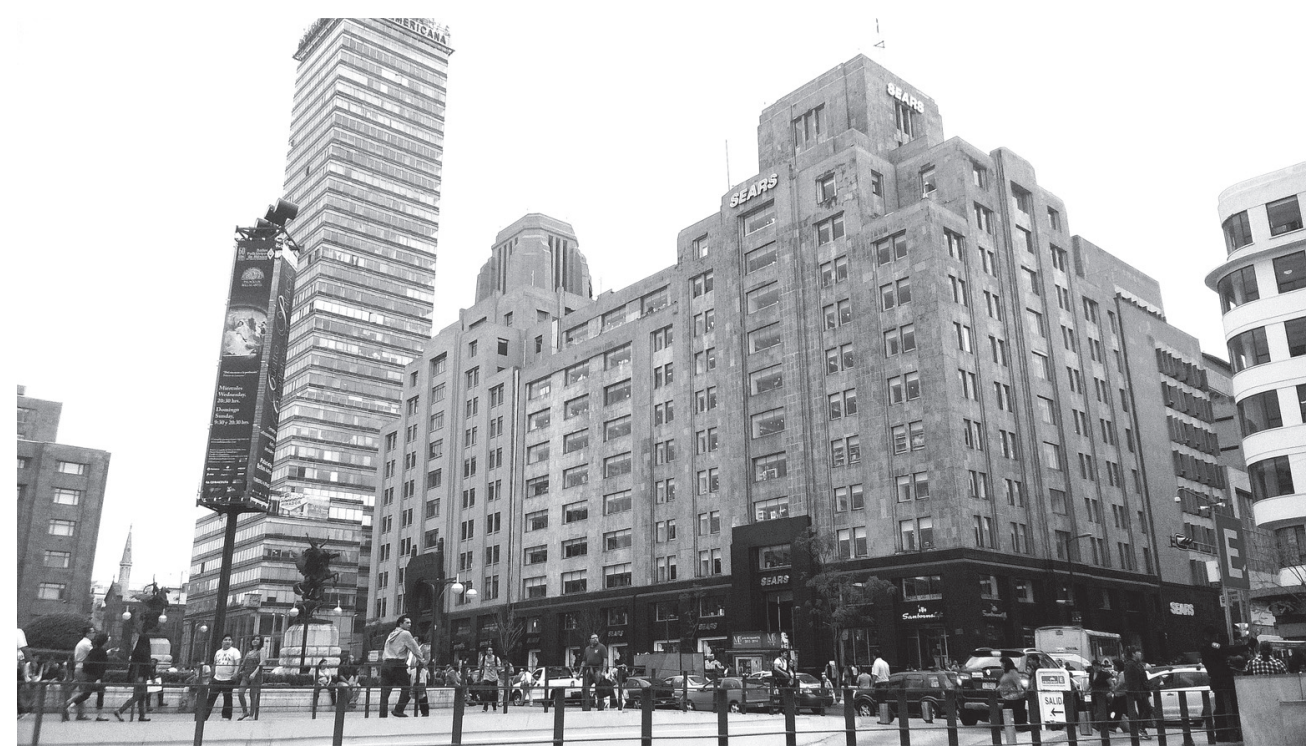

Fuente: Archivo personal de Patricia Olivera, abril de 2014.

en venta como en alquiler entre 2000 y 2006 , alrededor de 2.176 dólares metro cuadrado en promedio de venta actual, con anterioridad no rebasaba los 100 dólares. Sin embargo, debido a los usos diferenciados: bodega, oficina, comercio, aun cuando están declarados como vivienda, generan sustitución de clase social de manera más específica. Hay que destacar que estos programas públicos de "recuperación" del patrimonio actuaron en menos del $10 \%$ de los inmuebles del Centro Histórico (en total hay alrededor de 9.000 predios y más de 1.500 edificios catalogados), los barrios habitados y deteriorados del norte y oriente son parte de próximas etapas gentrificadoras (Entrevista con funcionario público, Patricia Olivera, 2012).

La política actual de "recuperación" del $\mathrm{CH}$ la dirige la "Autoridad del Centro Histórico", la cual promueve grandes comercios y operadores turísticos, para nuevos consumidores de mayores ingresos ${ }^{16}$. El "Plan

\footnotetext{
16 Cabe destacar que la primera funcionaria que se desempeñaba como Autoridad del $\mathrm{CH}$ fue integrante de la "Fundación Centro Histórico", propiedad de Slim.
}

Integral de Manejo del Centro Histórico 2011-2016" (Jefatura de Gobierno, 2011) se propone regularizar el registro catastral y la propiedad del suelo, ajustar sus valores, así como desarrollar de manera secuencial los barrios del $\mathrm{CH}$ a partir de las Ilamadas Zonas de Actuación (ver Figura $N^{\circ} 1$ ). Se trata de disciplinar las actividades y los usos del suelo para garantizar un Centro Histórico higiénico, seguro y limpio, sin embargo, estas políticas apuntan a una privatización del espacio patrimonial, a través del conjunto de normativas público- privadas.

\section{El barrio de Regina, Centro Histórico}

El barrio de Regina, en el sur del Centro Histórico (Figura $N^{\circ} 3$ ), se ha convertido en un interesante laboratorio urbano y social en donde de manera privilegiada se evidencian las tensiones entre los nuevos residentes y consumidores de clase media, con los antiguos habitantes de bajos ingresos. Se trata de un barrio dañado por los sismos de 1985, donde el programa de Renovación Habitacional Popular, entre 1986 y 1987, rehabilitó y reconstruyeron 36 edificios con viviendas de interés social. Regina se puso de "moda" en 2002 por las acciones de remodelación del 
Centro Histórico: rehabilitación del espacio público, mejoramiento de infraestructura, peatonalización de la calle, creación del jardín público Sor Juana Inés de la Cruz, reubicación de vendedores ambulantes e indigentes, la introducción de fuertes medidas de seguridad, fomento de actividades culturales en el "espacio público" Casa Vecina, propiedad de Slim; incremento de cafés, restaurantes, bares y galerías financiadas por este inversionista, donde adquirió 19 inmuebles, varios de ellos fueron remodelados y ofertados como vivienda para nuevos residentes de clase media. Leal (2007) retrata claramente la construcción público-privada del nuevo paisaje urbano en Regina, por una parte destinado al consumo de jóvenes foráneos: el fomento de negocios, actividades artísticas y culturales, un sistema de seguridad privada y pública, y la apertura de nuevos espacios de entretenimiento; y por otro, la llegada de nuevos residentes: estudiantes, artistas, promotores culturales y jóvenes profesionales (Leal, 2007: 28) y gerentes de empresas inmobiliarias, entre otras, todos ellos atraídos hacia el Centro Histórico a partir de los proyectos inmobiliarios. En el barrio existe una creciente promoción privada-pública para el consumo de clases medias, transformando este espacio subutilizado y habitado por población de bajos ingresos. Las acciones públicas señalan que no se busca la exclusión y el desalojo de la población residente de bajos ingresos. Sin embargo de acuerdo con la evolución de este barrio surgen las preguntas: ¿Las viviendas sociales reconstruidas y rehabilitadas después de los sismos se gentrificarán? ¿La población residente de bajos ingresos permanecerá en el barrio renovado o seguirá siendo desplazada por nuevas actividades y residentes? En 2011 en la calle Regina se registraron anuncios de venta de departamentos, algunos son viviendas sociales en monumentos históricos rehabilitados después de los sismos. Sin embargo, se monitoreó el portal "Vivir en el Centro" que forma parte del Fideicomiso Centro Histórico para promocionar la oferta de alquiler y venta de inmuebles en el Centro Histórico y se encontró que en agosto de 2011 había 85 ofertas de vivienda e inmuebles en venta, entre ellas en Regina 27, vivienda de 60 metros cuadrados en un edificio histórico rehabilitado como vivienda social después de los sismos de 1985, se vendía en 48.000 dólares.
En Regina 31 con 42 metros cuadrados se vendía en 66.400 dólares, en Bolívar 69 con 95 metros cuadrados se vendía en $76.000^{17}$. En agosto de 2013 había 54 ofertas de viviendas e inmuebles en venta, de las cuales 7 se ubican en Regina ${ }^{18}$, continuaban ofertando los mismos departamentos de Regina, cuatro departamentos en un inmueble remodelado en Mesones 180, entre 46.800 dólares (50 metros cuadrados) y 115.200 dólares (ver portal www.vivirenelcentro.com.mx). En septiembre de 2013 se añaden a lo anterior dos edificios no remodelados: Edificio Topacio de 3 niveles con 11 departamentos, edad de 50 años y terreno de $368 \mathrm{~m}^{2}$ y el de 11 locales de cortina, edad de 30 años y terreno de $433 \mathrm{~m}^{2}$. Se indica que son construcciones no catalogadas por INAH-INBA (disponible en portal de Trovit inmobiliaria, consultado el 18 de septiembre de 2013). Existen indicios de declive en el mercado inmobiliario, se seguirá monitoreando.

La revisión de cambios sociodemográficos no ofrece datos concluyentes: entre 1990 y 2010 el barrio de Regina redujo su población residente y el número de viviendas censadas (Cuadro $N^{\circ} 3$ ), no obstante las pérdidas son mucho mayores entre 1990 y 2000. El promedio de años de escolaridad en este barrio ascendió de 9 a 10,46 años entre 2000 y 2010. Respecto a los cambios en los grupos etarios, indican que los niños de 0 a 4 años casi se redujeron a la mitad de 1990, el grupo de 5 a 14 años se incrementó considerablemente, el grupo de 15 a 59 años descendió abruptamente, mientras que los adultos mayores de 60 años se incrementaron en poco más de 4 puntos porcentuales, la población y el número de viviendas continúa en declive (Cuadro $\left.\mathrm{N}^{\circ} 4\right)$.

\footnotetext{
1769 ofertas se ubicaron en un edificio nuevo en el sur de la Alameda (Iturbide 32) con departamentos de entre 78.400 y 88.000 dólares para departamentos de 60 a 70 metros cuadrados, respectivamente.

1834 ofertas se ubican en el mismo edificio nuevo en el sur de La Alameda (Iturbide 32) con departamentos de entre 78.400 y 126.800 dólares para departamentos de 56 a 90 metros cuadrados, respectivamente.
} 
Cuadro $\mathrm{N}^{\circ} 3$

Población y Vivienda en Regina 1990-2010

\begin{tabular}{|l|r|r|r|r|r|r|r|r|}
\hline \multirow{2}{*}{ Colonia } & \multirow{2}{*}{$\begin{array}{c}\text { Área } \\
\text { (Has) }\end{array}$} & \multicolumn{2}{|c|}{1990} & \multicolumn{2}{c|}{2000} & \multicolumn{2}{c|}{2010} \\
\cline { 3 - 9 } & Población & Vivienda & Población & Vivienda & Población & Vivienda $\begin{array}{c}\text { Habitantes/ } \\
\text { vivienda }\end{array}$ \\
\hline Regina & 61,70 & 8.354 & 2.131 & 5.771 & 1.591 & 5.122 & 1.555 & 3,3 \\
\hline
\end{tabular}

Nota: * Habitantes por vivienda

Fuente: Víctor Delgadillo, elaboración propia en base a Censos del INEGI, 1990, 2000 y 2010.

Cuadro $\mathrm{N}^{\circ} 4$

Población relativa por grupos etarios en Regina 1990-2010

\begin{tabular}{|l|r|r|r|r|r|r|r|r|r|r|r|r|}
\hline Edad & \multicolumn{3}{|c|}{0 a 4} & \multicolumn{3}{c|}{5 a 14} & \multicolumn{3}{c|}{15 a 59} & \multicolumn{3}{c|}{60 años y más } \\
\hline Colonia & 1990 & 2000 & 2010 & 1990 & 2000 & 2010 & 1990 & 2000 & 2010 & 1990 & 2000 & 2010 \\
\hline Regina & 9,47 & 7,14 & 5,51 & 4,86 & 14,95 & 12,34 & 75,02 & 65,26 & 67,29 & 10,65 & 12,65 & 14,86 \\
\hline
\end{tabular}

Fuente: Víctor Delgadillo, elaboración propia en base a Censos del INEGI, 1990, 2000 y 2010, Aguascalientes.

\section{Ciudad Progresiva, Delegación Benito Juárez}

Mitikah es un controvertido megaproyecto por la forma en que ha sido gestionado por el Grupo Ideurban. Se ubica en la céntrica Delegación Benito Juárez en lo que fueran terrenos del pueblo de Xoco y posteriormente del centro financiero Bancomer, relocalizado en Paseo de la Reforma. El desarrollo privado Mitikah incluye una clínica, un hotel, 500 departamentos de lujo, plazas de esparcimiento, centro comercial, cines y oficinas en un conjunto de 7 edificios con alturas de 12 a 32 niveles y una torre de 60 niveles y 290 metros de altura, diseñada por el arquitecto César Pelli, cuenta con un helipuerto y seis niveles subterráneos para estacionamiento. Se ubica en el Circuito Bicentenario, en el límite de las delegaciones Coyoacán y Benito Juárez, una zona saturada vialmente con conectada por vialidades y sistemas de transporte. Las protestas de los habitantes del adyacente barrio de Xoco se dirigen contra el tráfico de influencias, la discrecionalidad en la modificación e intensidad en los usos del suelo. En la zona se permitían hasta 6 niveles de construcción y se autorizaron 60 pisos para la torre Mitikah, 167 metros. Los vecinos manifiestan daños en las estructuras edificadas de iglesia y viviendas en el barrio y la impunidad con que la que actúan tanto la inmobiliaria Ideurban, como los funcionarios públicos, puesto que se han realizado denuncias penales, con la suspensión temporal de la obra, al reanudarse se han presentado amenazas a los vecinos. El antiguo pueblo de Xoco ha sido cercado por los desarrollos inmobiliarios que han incrementado sus problemas de saturación vial y el deterioro de la vida barrial. Los vecinos enfrentan condiciones desfavorables contra los poderes conjugados de empresarios inmobiliarios y autoridades insensibles.

\section{Las colonias Roma, Condesa e Hipódromo}

En las dos últimas décadas estas tres colonias históricas se han convertido en un referente de la ciudad por el incremento de la oferta cultural, gastronómica, comercial y de entretenimiento, y por la oferta residencial dirigida al consumo de las clases medias y medias-altas. Estas tendencias han sido promovidas o reforzadas por las políticas públicas recientes. Las tres colonias surgieron a principios del siglo XX, en el marco de la expansión urbana de la Ciudad de México, la cual impulsaba la producción y comercio cuyo orden espacial se adecuaba a las nue- 
vas exigencias económicas, pero también a las ideológicas que imponían normas, modas y gustos estéticos. De la Torre (2006) sugiere que la elite porfirista gobernante de principios del siglo XX se propuso imitar los modelos de urbanización de las ciudades europeas. Así, estas colonias de clase media y alta aspiraban a la construcción de una "ciudad moderna" ("rinconcitos" de París, Berlín o Bruselas) contando con amplias calles, camellones centrales arbolados, jardines públicos, parques, mercados y escuelas; así como calidad en la infraestructura de pavimentos, agua y drenaje.

Hacia las décadas 1950 y 1960 estas colonias dejaron de ser barrios residenciales de lujo. Las elites comenzaron a desplazarse a Polanco, Anzures y Lomas de Chapultepec y después a La Herradura. Se comenzaron a construir edificios de menor calidad y seguridad pero con mayor altura, en sustitución de casas unifamiliares, para satisfacer las necesidades de vivienda de una creciente población, así como escuelas, cines, comercios, servicios y tiendas departamentales. Las consecuencias de los sismos de 1985 aceleraron su despoblamiento y abandono; se evidenció que varios edificios se habían convertido en vecindades. Tavares (1995) describe a la Roma como una colonia que lentamente se sobreponía a los efectos de los sismos, había una mezcla de usos del suelo que combinaba la vivienda con hoteles, oficinas, talleres, sanatorios y clínicas, colegios y escuelas. Mientras que Porras (2001) acusaba que debido a la terciarización de la colonia Condesa, había una serie de conflictos entre una población fluctuante (estimada en 30 mil personas diarias) que duplicaba a la población residente. Los intereses encontrados entre residentes, trabajadores y usuarios se expresaban en protestas públicas: unos defendían su derecho al trabajo y otros a residir en una tranquila zona habitacional. Ambos autores destacan que a pesar del proceso de sustitución edilicia que de manera acelerada ocurrió y rompió con el carácter ecléctico del paisaje urbano, aún se conservaba un rico patrimonio urbano arquitectónico constituido por edificios Art Nouveau, Art Decó, funcionalistas, neocoloniales y californianos. Varios autores coinciden en que el renacimiento de estas tres colonias a principios de la década de 1990, no fue una acción planificada por el gobierno sino una "operación hormiga" (González, 2008) realizada por nuevos residentes e inversionistas, quienes encontraron precios accesibles y un atractivo entorno urbano para residir, producir y trabajar, lo que posteriormente fue atrayendo a más consumidores, usuarios e interesados en invertir. Cada colonia ha evolucionado de manera diferente:

- Para Salinas (2013) en la Condesa en 1990 comenzaron a proliferar restaurantes, oficinas y se hizo evidente el retorno de población (antigua y nueva) para residir allí, en esta época se comienzan a reciclar antiguos edificios en modernas viviendas en departamentos.

- Porras (2001) denunciaba a principios del siglo XXI que el boom de bares, comercios, cafés, restaurantes y cabarets en la Hipódromo había ampliado la vida nocturna, y que este éxito profundizó los problemas urbanos y los conflictos entre los residentes y usuarios.

- Quiroz (2012) ubica a mediados de la década de 1990 el inicio de la revalorización en la Roma, con el apoyo de algunos proyectos emblemáticos: la apertura de la Casa Lamm, un centro cultural privado y la rehabilitación del edifico Balmori con departamentos de lujo. A ello se suma el "Corredor Cultural", con cuatro galerías de arte (Casa Lamm, OMR, Nina Menocal y la Universidad de la Comunicación), hacia 1995, "cuando la Roma se encontraba muy deteriorada y abandonada" por los efectos de los sismos de 1985. Estos recorridos pretendían atraer a la gente a consumir cultura y entretenimiento.

La intensificación de la actividad inmobiliaria promovida por las políticas de liberalización con el Bando 2 explica las transformaciones de estas antiguas colonias, encarecidas por el auge de los desarrolladores, la proliferación de nuevas actividades y usuarios y residentes alteraron la vida cotidiana: saturación de comercios y del espacio público; incremento del tráfico y congestión vial; estacionamiento en la vía pública; ruido; ocupación de las banquetas por los restaurantes, cafés y bares. Los conflictos recientes de la población residente con el gobierno local (con actitud permisiva frente a los cambios que ocurren en esas colonias) destacan: la instalación de parquímetros, la regulación 
del trabajo informal de los cuidadores de autos y la lucha por cancelar desarrollos inmobiliarios habitacionales y comerciales. Recientemente se emprendido la política de impulso al turismo y se declararon 21 "barrios mágicos", dentro de ellos La Merced, Garibaldi, en el Centro Histórico, asimismo Roma, Condesa-Hipódromo.

En la Roma, Quiroz (2012) destaca una doble problemática simultánea: el deterioro físico de varios inmuebles antiguos, vivienda tugurizada habitada por población de bajos ingresos, infraestructura obsoleta, despoblamiento, abandono del espacio público e incremento de la inseguridad pública. Y por otro lado, un proceso de revalorización urbana, reactivación económica y redensificación habitacional.
En la Condesa, Salinas (2013) da cuenta de la saturación de las actividades gastronómicas que rebasa a las autoridades. Los cambios de uso del suelo para los comercios y servicios ocurren de manera formal e informal. El autor indica que desde 2005 estas tendencias se han exacerbado, los nuevos comercios, restaurantes (en las avenidas Michoacán y Tamaulipas) y servicios han ganado un enorme peso en detrimento de la función habitacional, mientras que los nuevos proyectos habitacionales rompen con el paisaje urbano: ahora se construyen con mayores alturas sobre baldíos o en sustitución de antiguos edificios, algunos con valor patrimonial. La sustitución de comercio tradicional e informal por comercio de marca, franquicias y departamental ocurre por medio de procesos gentrificadores en ciudades de América Latina y Europa (González y Waley, 2012).

Figura $\mathrm{N}^{\circ} 3$

Proyectos inmobiliarios con procesos de gentrificación en Ciudad de México, algunos ejemplos

Poligonos que contienen proyectos inmobiliarios con procesos de gentrificación en la ciudad de México, algunos ejemplos.
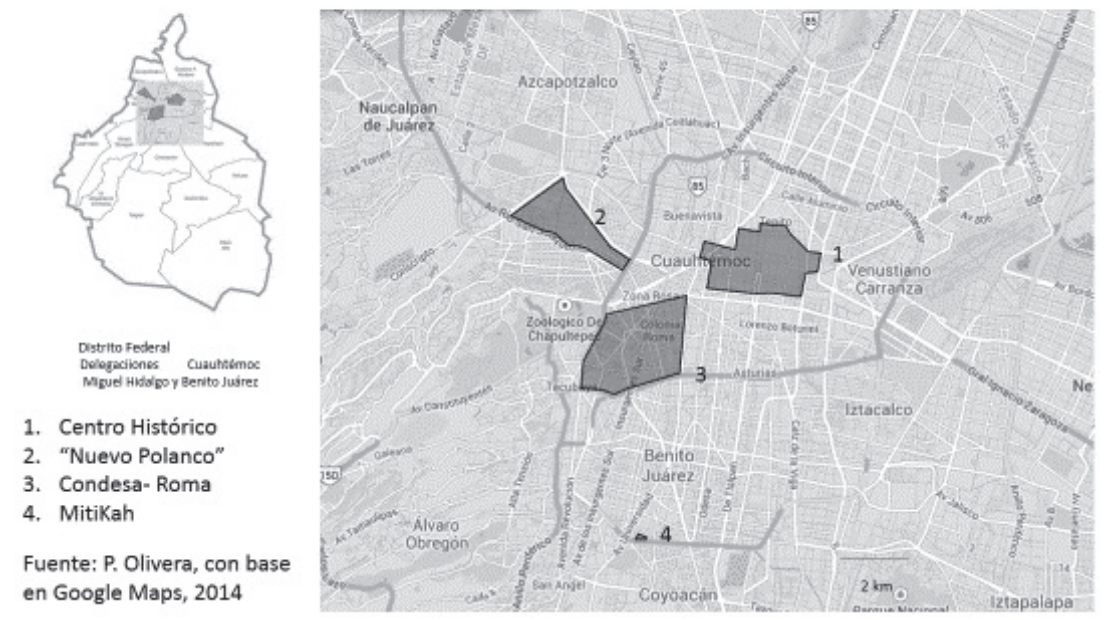

Fuente: Patricia Olivera en base a Google Maps, 2014.

En este contexto de creciente inversión en la Ciudad de México se suman la coIonia Condesa, Hipódromo, cercanas a la Zona Rosa"19, por lo que ahora las presiones

\footnotetext{
${ }^{19}$ Distrito turístico y de entretenimiento nocturno creado en la década de 1950 en una antigua colonia céntrica vecina a la Condesa y la Roma.
}

económicas y las actividades culturales, gastronómicas, de servicios y también residenciales se trasladan a la colonia Roma, donde los valores del suelo son relativamente más accesibles. En este sentido, Quiroz (2012) destaca que un indicador del desplazamiento de las actividades culturales y económicas a la Roma, lo constituye la avenida Colima, donde crece la nueva vivienda y el comercio 
nuevo avanzaba sobre el comercio tradicional. Entre 1990 y 2010 las tres colonias redujeron el $25,88 \%$ de su población residente (Cuadro $\mathrm{N}^{\circ}$ 5), pero las pérdidas son mucho mayores entre 1990 y 2000: La Roma perdió 7.625 habitantes pero en la última década ganó 589 residentes. La Hipódromo perdió 2.247 habitantes pero en la última década ganó 537 habitantes. Mientras que La Condesa perdió población en ambos períodos. El proceso de pérdida de vivienda en la década de 1990 se revirtió entre 2000 y 2010 . En ese período, el promedio de escolaridad ascen- dió en las tres colonias. En La Condesa pasó de 12,4 a 14,06 años; en La Hipódromo de 12,8 a 14,26 años; y en La Roma de 11,68 a 13,34 años. Por su parte, los cambios en los grupos etarios (Cuadro $\mathrm{N}^{\circ}$ 6) muestran que en la última década, los niños de 0 a 4 años y de 5 a 14 años disminuyeron su proporción entre 3 y 4 puntos porcentuales, mientras que la población de 15 a 59 años incrementan su proporción entre 2 y 5 puntos porcentuales, debido a que está Ilegando población joven a estos barrios (Salinas, 2013).

Cuadro $N^{\circ} 5$

Población y Vivienda en 3 colonias históricas 1990-2010

\begin{tabular}{|l|r|r|r|r|r|r|r|r|}
\hline \multirow{2}{*}{ Colonia } & \multirow{2}{*}{$\begin{array}{c}\text { Área } \\
\text { (Has) }\end{array}$} & \multicolumn{2}{|c|}{1990} & \multicolumn{2}{|c|}{2000} & \multicolumn{3}{|c|}{2010} \\
\cline { 3 - 9 } & & Población & Vivienda & Población & Vivienda & Población & Vivienda & $\begin{array}{c}\text { Habitantes/ } \\
\text { vivienda }\end{array}$ \\
\hline Condesa & 88,93 & 15.196 & 4.689 & 13.159 & 4.623 & 11.797 & 4.878 & 2,4 \\
Hipódromo & 127,90 & 15.113 & 4.763 & 12.149 & 4.451 & 12.686 & 5.385 & 2,4 \\
Roma & 370,90 & 51.721 & 15.366 & 43.507 & 14.405 & 44.096 & 17.055 & 2,6 \\
\hline
\end{tabular}

Fuente: Víctor Delgadillo, elaboración en base a Censos del INEGI.

Cuadro $\mathrm{N}^{\circ} 6$

Población relativa por grupos etarios en 3 colonias históricas 1990-2010

\begin{tabular}{|l|r|r|r|r|r|r|r|r|r|r|r|r|}
\hline Edad & \multicolumn{3}{|c|}{0 a 4} & \multicolumn{3}{c|}{5 a 14} & \multicolumn{3}{c|}{15 a 59} & \multicolumn{3}{c|}{60 años y más } \\
\hline Colonia & 1990 & 2000 & 2010 & 1990 & 2000 & 2010 & 1990 & 2000 & 2010 & 1990 & 2000 & 2010 \\
\hline Condesa & 6,98 & 4,88 & 3,59 & 3,45 & 10,36 & 6,61 & 75,06 & 68,93 & 72,70 & 14,51 & 15,84 & 17,10 \\
Hipódromo & 6,88 & 4,86 & 3,97 & 3,47 & 9,90 & 5,91 & 75,52 & 70,78 & 76,16 & 14,13 & 14,46 & 13,96 \\
Roma & 7,76 & 5,59 & 4,31 & 3,79 & 12,03 & 8,82 & 75,12 & 68,61 & 71,95 & 13,33 & 13,76 & 14,92 \\
\hline
\end{tabular}

Fuente: Víctor Delgadillo, elaboración en base a Censos del INEGI.

\section{Nuevo Polanco}

A partir de la década de 1930, producto de la política de industrialización y sustitución de importaciones, en el norte de Polanco se establecieron grandes empresas fordistas de producción automotriz, entre otras. En la década de 1960 los residentes de Polan-
$\mathrm{CO}^{20}$ comenzaron a organizarse para defender su barrio residencial porque percibían la rápida alteración de los usos habitacionales,

\footnotetext{
20 Polanco es un barrio de clase alta edificado por la burguesía comercial extranjera asentada en México, judíos, españoles, libaneses, así como la elite local.
} 
el incremento de pequeños comercios, oficinas de servicios, restaurantes, así como la densificación de vivienda plurifamiliar, generándose conflictos y saturación de vialidades después de la edificación de los Hoteles Presidente (1972) y del Nikko (1986) en Paseo de la Reforma. A partir de la activa presencia y movilización de colonos de clases altas, en 1992 el gobierno del Distrito Federal creó la Zona Especial de Desarrollo Controlado Polanco (posteriormente Ilamada Programa Parcial de Desarrollo Urbano de Polanco ${ }^{21}$ con la finalidad de ordenar y regular los usos e intensidades y evitar el deterioro de las edificaciones (Olivera, 2013).

En el marco del proceso de restructuración industrial en la Ciudad de México desde la década de 1980, las plantas fordistas se reestructuraron, fusionaron o quebraron, un ejemplo de esto es la planta Chrysler, abandonada y demolida en 2004, la cual se relocalizó en el norte del país, debido a que en el contexto del Bando 2, con la revalorización del suelo en particular en las delegaciones centrales, los dueños de la planta decidieron la promoción habitacional, aprovechando la localización del predio dentro de la estructura urbana de la Ciudad de México y la propiedad del suelo, el valor estético, histórico, la calidad de las edificaciones aledañas y la normatividad local, por lo cual la vivienda se dirigió a las clases medias-altas (entre 10 y 30 salarios mínimos de ingreso familiar), con lo cual se desarrollaron varios megaproyectos en las colonias industriales y de clase obrera al norte de Polanco, en la Delegación Miguel Hidalgo, denominados "desarrollos urbanos integrales" con usos mixtos de vivienda, servicios corporativos, recreativos, banca, restaurantes, comercios (Olivera, 2013), entre ellos, en 2005 se inició el megaproyecto inmobiliario Plaza Antara, de Promotora Los Atrios y Walton St. Capital (en la colonia Granada), en 2008 Plaza Carso 22. En 2011 Polárea, promovido

21 Gaceta Oficial del Distrito Federal el 15 de enero de 1992 y ratificado en 1997.

22 Se compone el Museo Soumaya, el Museo Jumex, el Teatro Cervantes, un centro comercial con las tiendas del grupo, hotel y entretenimiento, torres corporativas y de vivienda de 22 niveles con departamentos desde 121 hasta 207 metros $^{2}$, cuyos precios oscilan entre 375.000 y 585.000 dólares (Olivera, 2013). por el grupo corporativo español $\operatorname{Lar}^{23}$, en 2012 (inicia pero entrega en 2015) Parques Polanco $^{24}$ (en la Colonia Granada), en 2008 se desarrollan La Quadra y Grand Polanco (en la colonia Irrigación) ${ }^{25}$, City Towers (en la colonia Ampliación Granada) con valores similares a los ejemplos anteriores. En contraste, los precios de departamentos fuera de este tipo de desarrollos disminuyen notablemente, oscilan entre 50.000 y 150.000 dólares con superficies variables entre 60 y $120 \mathrm{~m}^{2}$. Asimismo, la oposición vecinal a estos proyectos de reciclamiento de usos urbanos y gran inversión es bastante diferenciada, la principal demanda de las clases altas de Polanco se refiere al control de los cambios de uso del suelo y calidad de edificaciones, en cambio las clases trabajadoras de las colonia ahora Ilamadas Nuevo Polanco se oponen a esos desarrollos por las carencias que padecen por el suministro de servicios básicos y perciben la invasión de empresas extranjeras, cuyos desarrollos mixtos sustituyen a las industrias y vivienda obrera (Olivera, 2013).

\section{Conclusiones}

El impulso a la "ciudad competitiva", los negocios y el desarrollo inmobiliario abarcan el espectro de políticas e incentivos para el desarrollo de nuevos enclaves de servicios globales, lo que implica la construcción de megaproyectos con usos mixtos, incluyendo de vivienda para clases medias y altas. La "recuperación" de barrios y centros históricos, la reconversión de la ciudad industrial por la modernización del capital flexible y la turistificación de enclaves de tiempo libre y negocios para usufructo del patrimonio histórico y espacios culturales por otros, define una estrategia excluyente, profundiza la ciudad desigual. El encarecimiento de las rentas urbanas está conduciendo al desplazamiento directo e indirecto de la población trabajado-

\footnotetext{
${ }^{23}$ En Polárea los departamentos en altura con superficies de $55 \mathrm{~m}^{2}$ a $100 \mathrm{~m}^{2}$ oscilan entre 150.000 a 353.000 dólares (Guía de Inmuebles, septiembre 2013).

${ }^{24}$ Departamentos en altura 20 niveles de 56 a $186 \mathrm{~m}^{2}$ con precios entre 185.000 y 558.000 dólares, en predio de $150.000 \mathrm{~m}^{2}$ (datos proporcionados por funcionaria de la empresa, septiembre 2013).

25 Departamentos en 385.00 dólares (Guía de Inmuebles, septiembre 2013).
} 
ra, quien ha tenido que emigrar a periferias urbanas distantes o a áreas rurales sin servicios ni infraestructuras, para alojarse en una vivienda y suelo barato. La revitalización de los barrios históricos en las colonias Roma, Condesa e Hipódromo Condesa constituye un proceso de reactivación comercial de la zona conducida por el mercado inmobiliario, con claros matices del imaginario. En contraste, la gentrificación más clásica por la cuantiosa inversión, el desplazamiento social violento y el interés en la modernización capitalista neoliberal corresponde a Santa Fe y respecto al desplazamiento indirecto a Nuevo Polanco, con grandes proyectos de servicios, comerciales y residenciales de una ciudad para los estratos más altos. En consecuencia con lo anterior, los procesos de inversión, sustitución de clase, crisis y declive urbano son apropiados por los agentes de la gentrificación en la ciudad de México, con formas, temporalidades e intensidades diferentes a los que se han presentado en las ciudades del capitalismo desarrollado. Identificamos al menos tres procesos de gentrificación en la Ciudad de México, con una morfología urbana igualmente diferente: la rehabilitación de una parte del Centro Histórico se asocia con la intensa participación del Estado y de grandes inversionistas privados, en una fusión prácticamente indisoluble, aprovechando ideológicamente la valorización simbólica muy arraigada en la sociedad mexicana, lo que correspondería a lo identificado por Janoschka et al. (2013) como gentrificación simbólica. La revitalización de los barrios históricos en las colonias Roma, Condesa e Hipódromo Condesa como un proceso de reactivación comercial, una gentrificación conducida por el mercado inmobiliario para el consumo. Y finalmente, la gentrificación más clásica, derivada de la cuantiosa inversión, el desplazamiento social violento y el interés en la modernización capitalista neoliberal que corresponde a Santa Fe un centro corporativo, y con desplazamiento indirecto el barrio denominado por Slim y otros desarrolladores "Nuevo Polanco" con grandes proyectos de servicios productivos, comerciales y residenciales para la ciudad global.

\section{Referencias bibliográficas}

BENLLIURE, P. La expansión urbana. Reciclamiento o desbordamiento. En: LEGO-
RRETA, J. (editor). La Ciudad de México a debate. México: UAM - Azcapotzalco, 2008, p. 63-95.

CARLOS, F. Espaço-tempo na metrópole: a fragmentação da vida cotidiana. São Paulo: Contexto, 2001.

CARSO. Carso impulsando el desarrollo. México: Real Estate, 2013.

CASGRAIN, A. y JANOSCHKA, M. Gentrificación y resistencia en las ciudades latinoamericanas. El ejemplo de Santiago de Chile. Andamios, 2013, № 22, p. 19-44.

DE LA TORRE, J. La ciudad de México en los albores del siglo XX. En: GONZALBO, P. (coordinador). Historia de la Vida cotidiana en México, Tomo V, Volumen II. México: FCE - El Colegio de México, 2006, p. 11-48.

DELGADILLO, V. Hábitat, centralidad y patrimonio en la Ciudad de México. En: COULOMB, R.; ESQUIVEL, M. y PONCE, G. (coordinadores). Hábitat y centralidad en México: un desafío sustentable. México D.F.: CESOP - Cámara de Diputados LXI Legislatura, 2013, p. 179-220.

DELGADILlO, V. Patrimonio histórico y tugurios, las políticas habitacionales y de recuperación de los centros históricos de Buenos Aires, Ciudad de México y Quito. México: UACM, 2011.

ESQUIVEL, L. La actuación de los desarrolladores habitacionales privados. En: TAMAYO, S. (coordinador). Los desafíos del Bando 2. Evaluación multidimensional de las políticas habitacionales en el Distrito Federal 2000-2006. México: SEDUVI-INVI- UACM, 2007, p. 253-289.

GONZÁLEZ, L. La construcción de lo cool en lo urbano. El caso de las condesas de la Ciudad de México. En: ÁlVAREZ, A. y VALVERDE, F. (coordinadores). Ciudad, territorio y patrimonio: materiales de investigación III. México: UIA - UV - UAG - BUAP, 2008, p. 185-206.

GONZÁLEZ, S. \& WALEY, P. Traditional Retail Markets: The New Gentrification Frontier? Antipode, Vol. 45, No 4, p. 965-983. 
HARVEY, D. From managerialism to entrepreneurialism: the transformation in urban governance in late capitalism. Geografiska Annaler, Series B, Human Geography, 1989, Vol. 1, $\mathrm{N}^{\circ} 71$, p. $3-17$.

HIDALGO, R. Los centros históricos y el desarrollo inmobiliario: las contradicciones de un negocio exitoso en Santiago de Chile. Scripta Nova. Revista Electrónica de Geografía y Ciencias Sociales, 2010, Vol. 85, № 331. Disponible en internet: http://www.ub.es/ geocrit/sn/sn-331/sn-331-85.htm

INSTITUTO NACIONAL DE ESTADÍSTICA, GEOGRAFÍA E INFORMÁTICA (INEGI). Censos de Población y Vivienda, 1990, 2000 y 2010, México: INEGI, 2010.

JANOSCHKA, M.; SALINAS, L. \& SEQUERA, L. Gentrification in Spain and Latin America - a Critical Dialogue. International Journal of Urban and Regional Research, 2013, Vol. 35, № 4, p. 1234-1265.

JARAMILLO, S. Reflexiones sobre las políticas de recuperación del centro (y del centro histórico) de Bogotá. Bogotá: CEDE-Universidad de los Andes, 2006.

JEFATURA DE GOBIERNO D.F. Plan Integral de Manejo del Centro Histórico de la Ciudad de México. Gaceta Oficial del Distrito Federal, 2011, № 1162, p. 3 - 125.

LEAL, A. Peligro, proximidad y diferencia: negociar fronteras en la Ciudad de México. Alteridades, 2007, №34, p. 27-38.

LENCIONI, S. Impasses da gestão metropolitana nas regiões de Buenos Aires, São Paulo e Santiago. Scripta Nova. Revista de Geografía y Ciencias Sociales, 2008, № 279, Vol. 59. Disponible de Internet: http://www. ub.edu/geocrit/-xcol/214.htm

LÓPEZ MORALES, E.; GASIC, I. y MEZA, D. Urbanismo Pro-Empresarial en Chile: políticas y planificación de la producción residencial en altura en el pericentro del Gran Santiago. Revista INVI, Vol. 28, No 76, 2012, p. $75-114$.
MORTEO, J. Ponencia en Taller Iberoamericano Vivienda en la ciudad central. México: Taller Iberoamericano de Vivienda, 2005.

PAQUETTE, C. Des habitants pour le centre historique? Mexico face á l'un des défis majeurs de la rehabilitation. In: RIVIERE D'ARC, H. \& MEMOLI, M. Le pari urbain en Amérique latine, vivre dans le centre des villes. Paris: Armand Colin, 2006, p. 107-125.

OLIVERA, P. Los centros corporativos y la gestión empresarialista en la ciudad de México. En: X Seminario Internacional de la Red Iberoamericana de Investigadores sobre Globalización y Territorio realizado en Querétaro, 2008.

OLIVERA, P. La ciudad y la gestión neoliberal en el caso de México. En: PEREIRA, P. (organizador). En: HIDALGO, R.; VIDAL-KOPFMANN, S. \& LENCIONI, S. (colaboradores). Negócios imobiliários e transformações socio-territoriais em cidades latino-americanas. São Paulo, Brasil: FAUUSP, 2011, p. 157181.

OLIVERA, P. Neoliberalismo y gentrificación en las ciudades norteamericanas. La Ciudad de México. En: OLIVERA, P. Polarización en la ciudad contemporánea. El re-escalamiento de los espacios del neoliberalismo. México: UNAM, 2013, p. 79-120.

PORRAS, J. Condesa Hipódromo. México: Clío, 2001.

QUIROZ, H. Extranjeros en el barrio: inmigrantes artífices y consumidores en la transformación reciente de la Colonia Roma, Ciudad de México. Academia XXII, 2012, № 4, p. 45-61.

RAMíREZ SÁIZ, J.M. Organizaciones populares y lucha política. Cuadernos Políticos, $1986, \mathrm{~N}^{\circ} 45$, p. 38-55.

SALINAS, L. Transformaciones urbanas en el contexto neoliberal. La colonia Condesa en la ciudad de México: hacia un proceso de gentrificación. México: UNAM, Tesis de Doctorado en Geografía, 2013.

SANTOS, M. Espaço dividido. São Paulo: Universidade do São Paulo, 2002. 
SMITH, N. The new urban frontier, Gentrification and the revanchist city. Londres: Routledge, 1996.

TAMAYO, S. Los desafíos del Bando 2. Evaluación multidimensional de las políticas habitacionales en el Distrito Federal 20002006. México: Gobierno del Distrito FederalUACM, 2007.

TAVARES, E. Colonia Roma. México: Clío, 1995. 
